$\xi=-1$

\title{
Corporate Social Responsibility (CSR): Assessing the Participant Perception Towards the Implementation of Sciencexplorer Programme
}

\author{
Aida Muhamad ${ }^{1 *}$, Ida Aryanie Bahrudin², Nor Faezah Adan ${ }^{3}$, Mohd Ezree Abdullah ${ }^{4}$, Muhammad Sufi Bin \\ Roslan ${ }^{5}$, Raudah Mohd Adnan', Zulkarnain Md Amin ${ }^{7}$ \\ 1,2,3,5,6,7 Centre For Diploma Studies, Universiti Tun Hussein Onn Malaysia \\ ${ }^{4}$ Faculty Of Civil And Environmental Engineering, Universiti Tun Hussein Onn Malaysia \\ *Corresponding Author E-Mail: Aidamohd@Uthm.Edu.Com
}

\begin{abstract}
Science, Technology, Engineering and Mathematics (STEM) subjects have always been complex subjects for school children as many experienced difficulty and complexity in grasping the basic conceptual knowledge. Therefore, Centre for Diploma Studies (CeDS) of Universiti Tun Hussein Onn Malaysia (UTHM) is moving forward to achieve sustainable development for society by pursuing Corporate Social Responsibility (CSR) through National Blue Ocean Strategy 4 (NBOS 4) initiatives. As a member of the society, CeDS try to ensure that the society will acquire the benefit of CeDS business activities as a whole.. ScienceXplorer programme had been implemented to attract primary school students in learning science. ScienceXplorer is a programme that basically implementing the concept of learning by doing. This study was performed to assess participant perception towards the implementation of ScienceXplorer. A selfcompletion questionnaire had been designed with a series of Likert scale questions that organized to gather participants' perceptions of participating ScienceXplorer. The questionnaire had been designed using Kirk Patrick Evaluation Model. There were 148 participants from three primary schools took part in this study. In this scope of study, ScienceXplorer participants rated very high in terms of reflection, knowledge and skill, changes in behaviour and aspiration.
\end{abstract}

Keywords: Voluntary Services; Social Responsible; Learning by Doing

\section{Introduction}

Across the years, the concept of Corporate Social Responsibility (CSR) has a long and varied history. Hamidu, Haron et al.(1) stated that the social responsibility of business includes economic, legal ethical and discretionary initiatives aspect that aimed at fulfilling stakeholder expectations. CSR can be defined as voluntary activities carried out by an organization to operate in an economic, social and environmentally sustainable manner. Over the decades, the concept and implementation of CSR has continuously grow in terms of its benefits and importance. Many companies define CSR by their activities where a single company may have different activities in different geographic regions (2). CSR also defines the ability of a company to be socially responsible to the growth and development of the environment in which it operates. It defines the voluntary services given by any organization to the society. In simple terms, CSR can be understood from the three words, "Corporate" which covers the large spectrum of businesses, "Social" refers to the local community with which they interact and finally by incorporating "Responsibilities" that are intrinsic on both sides of these relationships (3-5) (6).

Recently in 2015, the government introduced a new initiative called Social Public-Private Partnership (SPPP). SPPP is a new social service model aimed at addressing social gaps by delivering high value at a lower cost and focuses on collective action between government and private sector (7). SPPP is a project under the National Blue Ocean Strategy (NBOS) led by Agensi Inovasi Malaysia (AIM). According to the Prime Minister Budget Speech (2017), the NBOS initiative has successfully saved RM3.5 billion from Government's expenditure. The Government Chief Secretary in his speech on the 8th Heads of Mission Conference (Hamsa, 2014) reiterate that NBOS is a strategy that should be continuously utilized as we come together and do things faster, in a cost effective manner, for the well-being of the nation.

According to Deshmukh et al. (8), education field today is facing many challenges such as standardized testing, strained budgets, teacher retention, and global workforce competition. Businesses have begun to take a more targeted approach in their CSR programmes and are seeking to impact areas that have a correlation with their own business goals. Chopra and Marriya (9) had concluded their research regarding the impact of CSR towards education in India by stated that the affected individuals, companies, and society at large are likely to benefit from CSR. The role of CSR in education is thus mitigating the skills gap with considerable experimentation, and learning-by-doing along the way. The education field that is highly considered in Malaysia is the Science, Technology, Engineering and Mathematics (STEM) field (Andrew, 2017). Massimo (2015) supported this statement by stating that STEM-based learning and disciplines are essential to support effective learning in non-STEM areas (creativity, critical thinking, problem solving, communication, collaboration) and to become competent and capable citizens in a technology-dependent society and globalized world. 
Despite the importance of STEM field in developing countries, Malaysia will face a serious shortage of human capital in science fields as the target for students enrolling in the stream is not being met annually at the school and tertiary levels (Nasa \& Anwar, 2016). The Ministry of Education also claimed that the average percentage of secondary school students who qualified for the science stream, based on their results of the previous Form 3 Lower Secondary Examination (PMR), only hovered around 30 per cent over the past 10 years, though Malaysia has been aiming for a 60:40 ratio of science/ technical/vocational and arts students since 1970 (Lyn, 2015). Therefore, according to O.C. (2016), in order to boost the STEM education success, a partnership between the government bodies, industry, philanthropist, schools, nongovernmental organisations and leading academic institutions, locally and internationally, needs to be realized. Therefore, a collaboration effort between UTHM and neighbouring primary schools have been initiated through CSR programme that is focused on learning Science in order to deliver better STEM outcomes.

\section{Study Background}

In every sense, education is one of the fundamental factors for developing country. It also plays a very crucial role in securing economic and social progress. According to Shift 1 of Malaysia Educational Blueprint 2013-2025 by Ministry of Education Malaysia (2013), education system in Malaysia will provide equal access to quality education at international standard. As the first step, Malaysia has put an effort to strengthen the quality of STEM education. For Science and Mathematics in particular, students will benefit from increased instructional time and an emphasis on practical applications of knowledge through laboratory and project-based work.

Despite all these initiatives, there are indicators showing that the system needs to be more competitive in today's changing world Out of the 74 countries participating in Programme for International Student Assessment (PISA) 2009, Malaysia performed in the bottom third for Reading, Mathematics, and Science $(10,11)$ In the PISA 2012 results, Mathematics scored 421 lower than OECD's (Organization for Economic Co-operation and Development) average score of 494 , Science mean score 420 lower than OECD's average score of 501, and Reading mean score 398 lower than OECD's average score of 496 (12). There were some Malaysian schools with performance above the OECD average, but the overall ranking was still below OECD's average thus Malaysia's overall ranking was 52nd place out of 65 participating countries (13).

Moreover, Malaysia will face a serious shortage of human capital in science fields as the target for students enrolling in the science stream is not being met annually at the school and tertiary levels (14). Trepidation towards the decreasing number of students that interested to take Science and Technology fields are the issues that need to be refined (15). The Ministry of Education also stated that the average percentage of secondary school students who qualified for the science stream only hovered around 30 per cent over the past 10 years, based on their results of the previous Form 3 Lower Secondary Examination (PMR), though Malaysia has been aiming for a 60:40 ratio of science/ technical/vocational and arts students since 1970 (16).

According to Lim (17), there are several factors underlying the declining enrolment and interest in Science subjects. These include limited awareness about STEM, perceived difficulty of STEM subjects, content-heavy curriculum, and inconsistent quality of teaching and learning as well as limited and outdated educational infrastructure. Based on the current situation of STEM education in Malaysia, an effort to implement a strategy towards transforming STEM education has been planned via collaboration between community and other agencies to support the teaching and learning process. This issue has also been reported in Wave 2 of Malaysia Educational Blueprint 2013-2025 (Ministry of Education Malaysia, 2013) in which the main focus is building on the foundations to improve the development of educational transformation. According to Kamalanathan (18), a lot needs to be done to meet the timelines and mission of the Blueprint's first wave. Therefore, ScienceXplorer programme was implemented in order to help the government in improving the advancement of science field among rural primary school by using the learning by doing approach. This study reported the analysis of participants' perception towards the implementation of ScienceXplorer programme.

\section{Implementation of Sciencexplorer Pro- gramme}

Practical/Hands-on experiments has the capability to enhance students' understanding on important theorethical knowledge in a much more fun environment. Students will be able to see a problem visually and thus easier for them to comprehend a theory. Adapted from the Learning by Doing (LBD) Model founded by John Dewey, this approach should be able to prepare students in facing future challenges besides indirectly improves their concentration and sensory skill (19). According to Ingmire (20), brain scans of students who took an LBD approach to learning science had activation in sensory and motor-related parts of the brain when they later thought about concepts such as angular momentum and torque. Activation of these brain areas was associated with better quiz performance by college physics students who participated in the research. There are many advantages gain from LBD concept especially in science subject. The followings are the benefits of LBD in science based on the research done:

i. LBD give a great benefit as initial stages of learning and in areas of science education that lend themselves to physical experiences (20).

ii. It promotes student engagement in learning activity (21).

iii. It brings opportunity to engage in practical work in an authentic real-world science context (22).

iv. Practical work of a more open-ended, investigative kind can develop students' tacit knowledge of scientific enquiry (23).

v. An important role of practical work is to help students develop links between observations and ideas (24).

vi. Students were able to retain knowledge longer (Resource Area For Teaching, 2013).

The selected target group for this programme is year-six students from three neighboring schools. The aim of this programme is to help them prepare for science subject paper in Primary School Achievement Test (abbreviated as UPSR), a major examination based assessment at primary school level. Hence, by the end of the programme, students should have deeper understanding on selected science topics covered. Furthermore, this programme provides additional learning time using various learning materials. These students formed in smaller groups of five to six have been given an opportunity to conduct six experiments, each runs for 20 to 30 minutes with guidance from the facilitators. Engaged facilitators consist of UTHM's lecturers, student ambassadors and aspiring undergraduate students. The engagement of student ambassadors and undergraduate students is in line with Shift 1 in Malaysia Education Blueprint 2015-2025 (Higher Education) which is to produce a holistic, balanced and entrepreneurship driven graduates. All experiments have been designed by experienced UTHM lecturers to meet the level of current year-six science subject syllabus. Each experiment has a different and specific outcome to prove selected science theories learned in class. The last experiment is the highlight of the programme whereby a competition is held among the groups with prizes awaiting for the winners. Figure 1 show the implementation structure of ScienceXplorer. 


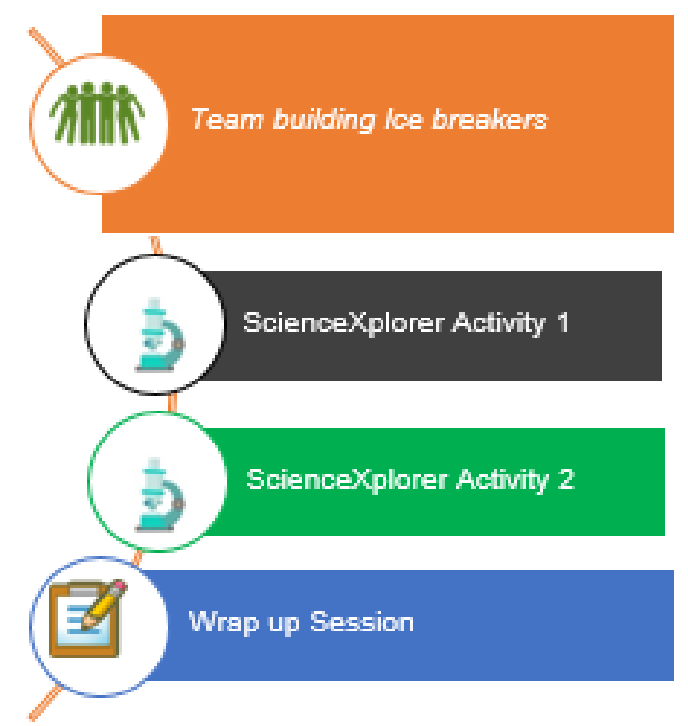

Fig. 1: Implementation Structure of ScienceXplorer

ScienceXplorer began with ice breaker session called "What Am I" adapted from Science Icebreaker Game: What Am I? (25). The activity started with an index card with science word taped on back of each student. Some examples of the science words are atom, cell, sun, gas and so on. The students were told that each word is a noun. Then, students go around asking a one yes or no question per person. For example, students can ask their friend a question like "Am I an animal?" which their friend can only answer yes or no to get the hints of the science word taped on their back. The first person to say their word wins the game. The activity continued until everyone has guessed their word. Students sat down as soon as they figure out their word. After the ice breaker session finished, ScienceXplorer activities started. The details of each activity is described in the following section. Wrap up session is a moment spend to reflect all the activities that had been done.

\section{Research Methodology}

\subsection{Research Design}

Experimental research was carried out between January 2017 and May 2017 in three selected primary schools in rural area in Batu Pahat, Johor, Malaysia. The research design consists of two parts; (i) the running of science activities based on year-six syllabus and (ii) the evaluation of participants' perceptions in learning science subject by survey questionnaires based on Kirk Patrick Evaluation Model. Kirk Patrick Model has now become the most widely used and popular model for the evaluation of training and learning (26). Kirkpatrick is an expert of training program evaluation in the human resource development context. The evaluation model developed by Kirkpatrick is known as Kirkpatrick's Four Levels Evaluation Model. Evaluation of the trainees' reaction refers to measurement of their level of satisfaction. A training program is regarded effective when it is pleasing and satisfying to the participants, so that they are motivated to learn and to exercise more (27). In other words, the trainees will be motivated when the training process runs in a satisfactory way and successfully invites gratifying responses from the participants. (26) suggests that learning can be defined as the extent to which participants change attitudes, improving knowledge, and/or increase skill as a result of attending the program. The participants are said to get something from the training when they show different attitude, improved knowledge, and improved skills. Kirk Patrick Evaluation Model consists of four evaluation levels such as reflection, knowledge and skill, changes in behaviour and aspiration. Kirk Patrick Evaluation Model consists of four evaluation levels such as reflection, knowledge and skill, changes in behaviour and aspiration. Reflection evaluation is how the participants felt, and their personal reactions to the training or learning experience, for example did the trainees like and enjoy the training or did they consider the training relevant. Knowledge and skill evaluation is the measurement of the increase in knowledge or intellectual capability from before to after the learning experience such as did the trainees learn what intended to be taught or did the trainee experience what was intended for them to experience. Behaviour evaluation is the extent to which the trainees applied the learning and changed their behavior, and this can be immediately and several months after the training, depending on the situation such as did the trainees put their learning into effect when back on the job or were the relevant skills and knowledge used. Aspiration evaluation is the effect on the environment resulting from the improved performance of the trainee.

\subsection{Participants}

A total of 148 year-six students from three primary schools in Batu Pahat, Johor, Malaysia rural area was selected as participants. The students were grouped into six groups. The selection of students in each group was done randomly.

\subsection{Experimental Procedures}

The unit of instruction used for this study involves six activities based on the year-six syllabus in preparation and consolidation for the UPSR examination for Science subject. This programme implements practical learning approaches based on the Learning by Doing (LBD) Model founded by John Dewey. This method allowed students to actively participate in practical activities that adapts theoretical knowledge into real world application.

The following activities were developed based on selected topics according to the year-six syllabus:

(i) Activity 1: Fun with Microscope

The students used microscope to see the cheek and onion cells. Explanation was given to the students.

\section{(ii) Activity 2: Fungal Morphology on Bread}

In this activity, the students used microscope to see the morphology of the fungi on the rotten food. Observation was made and the explanation was given to the students.

\section{(iii) Activity 3: Yeast Blow up Balloon}

In this activity, the students filled the bottle up with about one inch of warm water. The yeast packet was then added and gently swirled the bottle a few seconds. The sugar was then added to the bottle and the mixture was swirled for a few seconds. The balloon was blown up a few times to stretch it out then was placed the neck of the balloon over the neck of the bottle. The balloon was then begun to inflate. The observation was made.

\section{(iv) Activity 4: Rocket Balloon}

Two chairs were positioned about 10 feet apart. The one end of the string was tied to one of the chairs. The students then prepared the straw. Two pieces of tape were placed on the straw. The string was then threaded through the straw. The loose end of string was then tied up tight to the other chair. The balloon was blown up and the end was hold so the air could not escape. The straw and balloon were moved to one end of the string. The balloon was then let gone. The balloon rockets across the string.

\section{(v) Activity 5: Build Your Own Compass}

Students were exposed to build their own compass using household materials. The important of finding direction were explained to students to be used in daily life. The compass could be built by using needle, magnet, polystyrene, and water. Firstly, rub needle with magnet in one direction for at least ten times. Secondly, put in the needle inside small piece of polystyrene and lastly place the polystyrene that has been inserted with needle into small cup containing water. Let the needle float and wait until it stop rotating. The needle that has been rub with magnet will merge with magnetic field of the earth and will show point of north and south direction of the earth. 


\section{(vi) Activity 6: Parachute Power}

Students were exposed to existence of air molecule at surrounding environment. The air molecule fill the surrounding us and keep changing direction. However, if any large surface capturing the air molecule, the air molecule will resist the motion. This concept were used in parachute system in airborne. Students were given a challenge to build safest parachute for if any living need to transport thus the parachute must be the most slowest to reach ground when release. The student were provided with garbage plastics, scissors, and thread to build a parachute mimicking an airborne.

Briefly, the implementation of the programme involved a total of six groups formed during the ice breaking session. Six stations, one for each activity were assigned at the designated location. Each group performed different activity in parallel session. The duration allocated for each activity was 25 minutes. After the completion of an activity, each group moved to another station until all groups completed all six activities.

\subsection{Instruments}

A quantitative research method was used in this study. The questionnaire structure was used as an instrument study with the purpose of collecting data survey. Data collection was done by distributing questionnaire using 4 point Likert scale; strongly disagree (1) until strongly agree (4) to measure the level of consent of respondents. The model used four levels of assessment includes Part 1: Reflection, Part 2: Knowledge and Skill, Part 3: Behavior and Part 4: Aspiration. This technique was chosen because it saves time, cost-effective and in line with the nature of the study population.

\subsection{Data Analysis}

The data obtained were analyzed by descriptive analysis that uses mean score as the evaluation parameters. By using descriptive analysis, the mean score of the evaluation shows that most of the participants strongly agreed that the programme have improved their knowledge, skill, behavior and also aspiration. Unit analysis for this research is targeted at students who are following the ScienceXplorer programme. Thus, the respondents would have experience in answering questionnaire with ease.

\section{Findings and Discussions}

At the end of the experiment, a total of 148 data were included in the analysis. In this study, several controllable factors were held constant. These includes duration of instruction, age of respondent, and topic of learning. There are four evaluation level including reflection, skills and knowledge, behavior changing, and aspiration based on Kirk Patrick Evaluation Model. The descriptive statistic model was used to evaluate the data based on respondent survey form.

Based on the statistical data as shown in Figure 2, 89.86\% of the respondents strongly agreed that the programme implementation interaction is very high. The statistical data suggests that the experienced instructor played a major role to conduct a good interaction with the students. Meanwhile, $86.48 \%$ respondents strongly agreed that this kind of programme should be organized frequently. Thus, it indicates that the hands-on activities performed in this programme is able to positively influence participants' interests to learn about science. This result is aligned with Holstermann, Grube et al.(28) whom based on the research findings suggests the needs to integrate hands-on activities in science curricula to gain students' interest. Higher interest can be gained among participants through implementation of hands on activities that involves engagement with technology (29). About $88.51 \%$ respondent strongly agreed with the programme contents whereby the contents were referred to the syllabus from the year-six Science text book. Since this programme was held at an appropriate timing as the students will be sitting for UPSR examination by the end of the year, they are much more alert on the course content and thus were able to appreciate and better adapt to the activities.

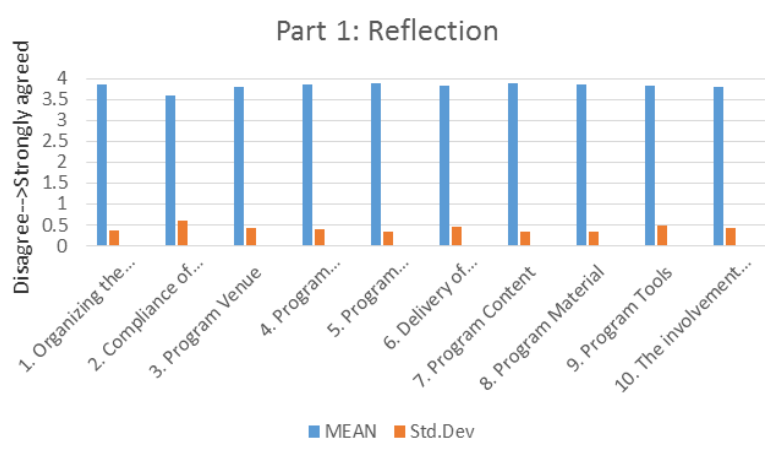

Fig. 2: Statistic of Programme Reflection Conducted Using Mean Score

The Knowledge and Skills statistical data is represented in Figure 3. In this study, $90.54 \%$ of respondent strongly agreed that this programme provide new knowledge for them. The activities allowed the students to feel and see the course material and so they were able to obtain deeper understanding on the topics covered. This response is in line with Korwin and Jones (30) who have long proven the positive effect of an organized psychomotor activities towards improving learning capability of participants for any applicable technological concept. The high percentage also reflects the increased level of confidence among participants in preparation for the upcoming UPSR examination. Meanwhile $95.95 \%$ of respondent strongly agreed that this programme improve knowledge needs in order to increase the quality of related task. It is observed that students were able to complete the following activity with ease and managed to show improved work quality as the programme progresses. This suggests that they have cumulated the necessary knowledge and practical skills by the end of the programme.

According to the statistical data, $87.84 \%$ respondent strongly agreed that this programme provides appropriate skills which is beneficial for general knowledge of science for daily life. Most of the materials used for the activities can be easily found at home and commonly used in our daily life purposely to show them how science revolves around us.

Part 2 (a): Knowledge

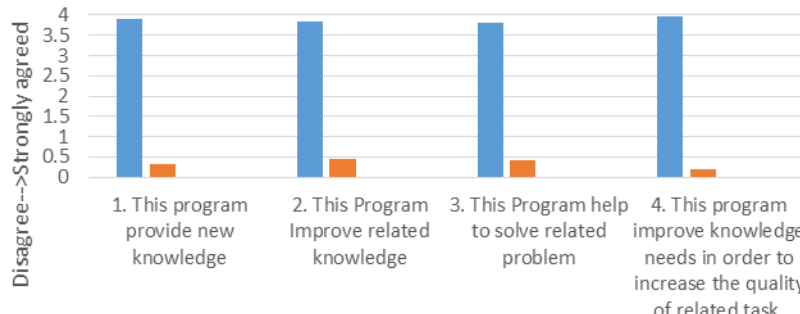

mEAN $=$ Std.Dev

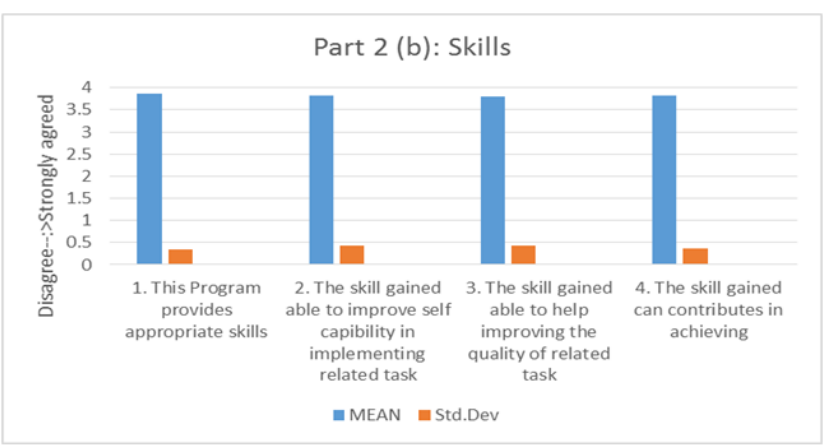

Fig. 3: Statistic of Skills and Knowledge Using Mean Score.

Figure 4 shows the statistical data for changing of behavior regarding to Programme ScienceXplorer. Based on the statistical 
data, $91.89 \%$ of the respondent strongly agreed that this programme can open a positive mind. Almost all students remained cheerful and energetic till the end of the programme which indicates a positive mind. The motivated instructors have also contributed in affecting students positively. According to the statistical data, $89.18 \%$ of the respondent strongly agreed that this programme help them become more productive while $86.48 \%$ strongly agreed that this programme pushes them to become more responsible. This can be observed from students' accomplishment in completing the tasks in a timely manner. This programme has successfully changed behavior of student from Low Order Thinking Skills (LOTS) to High Order Thinking Skills (HOTS).

Part 3: Behavior Changing

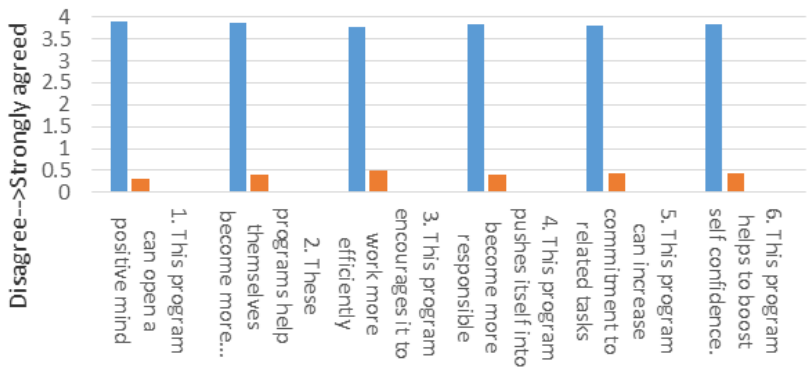

mEAN $=$ Std.Dev

Fig. 4: Statistic of Behavior Changing Using Mean Score.

Figure 5 shows the statistical data of mean score for Aspiration level of the student from ScienceXplorer Programme. Refer to the statistical data, $87.16 \%$ of the respondent strongly agreed that achievement of programme goals has been successfully accomplished. Among the students, $88.51 \%$ respondents strongly agreed that the programme benefits them while $89.19 \%$ strongly agreed the programme flows according to plan. This statistical data shows that the programme flows accordingly and achieved the target.

Part 4: Aspiration

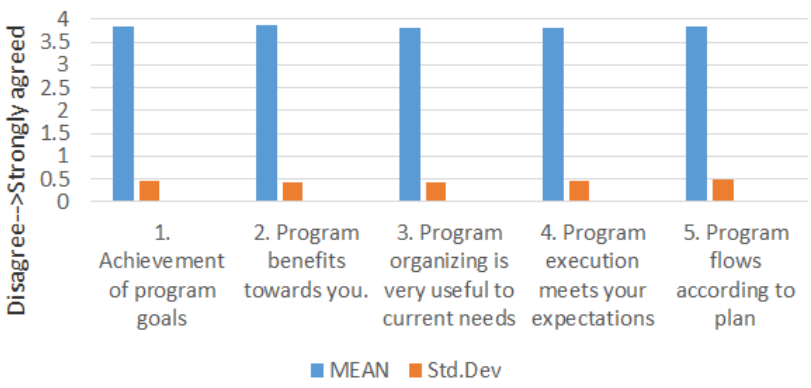

Fig. 5: Statistic of Aspiration Using Mean Score.

Based on the open-ended question, students were excited to learn different science experiments in the programme. Some of the comments written were, "This programme must be executed every year". Response gathered from an informal interview with the participating students suggests that generally they were more encouraged to learn in an informal class compared to traditional class using chalk and whiteboard, whereby some aspects were difficult to explain without demonstration. In this case, maintaining students' interest and focus during learning sessions becomes a major challenge for primary school in order to achieve better result in UPSR examination.

\section{Conclusion}

In summary, this study concluded that the implementation of ScienceXplorer as one of the CSR effort had contributed a great benefit to the participant. According to the four evaluations level that explained in previous section, more than $85 \%$ of the respondents agreed that this programme had contributed benefits in terms of their knowledge, skills, behavior and also aspiration. Therefore, the benefit of collaboration between agencies in order to improve STEM education produced a meaningful output. As mentioned by O.C. (2016), the extensive partnerships in implementing CSR provide the capacity to achieve what may not otherwise be achieved by a single authority. Working together in partnerships can deliver better STEM outcomes.

\section{Acknowledgement}

A special thanks to Research, Innovation, Commercialization and Consultancy Management (ORICC), Universiti Tun Hussein Onn Malaysia and Ministry of Higher Education Malaysia for supporting us in ScienceXplorer programme through the implementation of National Blue Ocean Strategy 4 (NBOS4).

\section{References}

[1] Hamidu AA, Haron M, Amran A. Corporate social responsibility: A review on definitions, core characteristics and theoretical perspectives. 2015

[2] Munro V. Stakeholder understanding of corporate social responsibility (CSR) in emerging markets with a focus on Middle East, Africa (MEA) and Asia. Journal of Global Policy and Governance. 2013;2(1):59-77.

[3] Alamer ARA, Salamon HB, Qureshi MI, Rasli AM. CSR's measuring corporate social responsibility practice in Islamic banking: A review. International Journal of Economics and Financial Issues. 2015;5(1S).

[4] Alamer ARA, Salamon HB, Qureshi MI, Rasli AM. How do We Measure Corporate Social Responsibility of Islamic Banks through their Business Processes and Oriented Outcomes? International Journal of Economics and Financial Issues. 2015;5.

[5] Alamer ARA, Salamon HB, Qureshi MI, Rasli AM. A New Business Process and Outcome Oriented Corporate Social Responsibility Index for Islamic Banking. International Journal of Economics and Financial Issues. 2015;5.

[6] Bhaduri SN, Selarka E. Corporate Governance and Corporate Social Responsibility of Indian Companies: Springer; 2016.

[7] Nasir NR, Subari MD. A Review of Social Innovation Initiatives in Malaysia. Journal of Science, Technology and Innovation Policy. 2017;3(1).

[8] Deshmukh P, Telrandhe R, Gunde M. Formulation and Evalua-tion of Herbal Toothpaste: Compared With Maeketed Preparation. Int J Pharm Drug Anal. 2017;5(10):406-10.

[9] Chopra A, Marriya S. Corporate social responsibility and education in India. 2014.

[10]Paltridge S. Organisation for Economic Co-operation and Development.(2009). Internet access for development. 2009.

[11]11. OECD. Organisation for Economic Co-operation and development. OECD Annual Report; 2009.

[12] MoE. Ministry of Education Malaysia. 2013.

[13] OEDC. Education at a Glance 2014: OECD indicators. OECD Publishing; 2014

[14] Nasa A, Anwar Z. Too few STEM student: New Straits Times; 2016 [Available https://www.nst.com.my/news/2016/05/147260/too-few-stemstudents.

[15]Arfudi IZ. Declining Number Of Malaysian Students Taking Science And Math In School, Here's Why. Malaysian Digest. 2016.

[16]Lyn BS. As 2020 deadline looms, Malaysian students fail to shine in science 2015 [Available from: http://www.themalaymailonline.com/malaysia/article/as-2020deadline-looms-malaysian-students-fail-to-shine-in-science.

[17]Lim CH. STEM Roadmap to Meet Growing Demand for Engineers in the Future, 2016 [Available from: http://www.myiem.org.my/content/press release-305.aspx.

[18] Kamalanathan P. Blueprint on track: The Star Online; 2014 [Available from: https://www.thestar.com.my/news/education/2014/08/31/blueprinton-track/.

[19]Gibbs G. Learning by doing: A guide to teaching and learning methods: FEU; 1988.

[20] Ingmire J. Learning by Doing Helps Students Perform Better in Science. 2015

[21]Prince M. Does active learning work? A review of the research. Journal of engineering education. 2004;93(3):223-31. 
[22] Alves CHC. Learning science through work experience: a Ciência Viva science internships programme for senior secondary students: University of Cambridge; 2007.

[23] Millar R. The role of practical work in the teaching and learning of science. High school science laboratories: Role and vision. 2004.

[24] Abrahams I, Millar R. Does practical work really work? A study of the effectiveness of practical work as a teaching and learning method in school science. International Journal of Science Education. 2008;30(14):1945-69.

[25] Vivify. Science Icebreaker Game: What Am I? 2015 [Available from: https://www.tes.com/teaching-resource/science-icebreakergame-what-am-i-11098828.

[26] Kirkpatrick DL. Another look at evaluating training programs: Fifty articles from training \& development and technical training: Magazines cover the essentials of evaluation and return-oninvestment: American Society for Training \& Development Alexandria, VA; 1998
[27]Badu SQ. The Implementation of Kirkpatrick's Evaluation Model in the Learning of Initial Value and Boundary Condition Problems. International Journal of Learning and Development. 2013;3(5):7488.

[28] Holstermann N, Grube D, Bögeholz S. Hands-on activities and their influence on students' interest. Research in Science Education. 2010;40(5):743-57.

[29] Swarat S, Ortony A, Revelle W. Activity matters: Understanding student interest in school science. Journal of Research in Science Teaching. 2012;49(4):515-37.

[30] Korwin AR, Jones RE. Do Hands-On, Technology-Based Activities Enhance Learning by Reinforcing Cognitive Knowledge and Retention? Journal of Technology Education. 1990;1(2):26-33. 